\title{
Electrostatics and polarization determine the strength of the halogen bond: a red card for charge transfer
}

\author{
Tore Brinck $^{1}$ (D) $\cdot$ André Nyberg Borrfors ${ }^{1}$
}

Received: 13 January 2019 / Accepted: 29 March 2019 / Published online: 24 April 2019

(C) The Author(s) 2019

\begin{abstract}
A series of 20 halogen bonded complexes of the types $\mathrm{R}-\mathrm{Br}^{\circ} \bullet \mathrm{Br}^{-}$( $\mathrm{R}$ is a substituted methyl group) and $\mathrm{R}^{\prime}-\mathrm{C} \equiv \mathrm{C}-\mathrm{Br}^{\circ} \bullet \mathrm{Br}^{-}$are investigated at the M06-2X/6-311+G(d,p) level of theory. Computations using a point-charge (PC) model, in which $\mathrm{Br}^{-}$is represented by a point charge in the electronic Hamiltonian, show that the halogen bond energy within this set of complexes is completely described by the interaction energy $\left(\Delta E^{\mathrm{PC}}\right)$ of the point charge. This is demonstrated by an excellent linear correlation between the quantum chemical interaction energy and $\Delta E^{\mathrm{PC}}$ with a slope of 0.88 , a zero intercept, and a correlation coefficient of $R^{2}=0.9995$. Rigorous separation of $\Delta E^{\mathrm{PC}}$ into electrostatics and polarization shows the high importance of polarization for the strength of the halogen bond. Within the data set, the electrostatic interaction energy varies between 4 and $-18 \mathrm{kcal} \mathrm{mol}^{-1}$, whereas the polarization energy varies between -4 and $-10 \mathrm{kcal} \mathrm{mol}^{-1}$. The electrostatic interaction energy is correlated to the sum of the electron-withdrawing capacities of the substituents. The polarization energy generally decreases with increasing polarizability of the substituents, and polarization is mediated by the covalent bonds. The lower (more favorable) $\Delta E^{\mathrm{PC}}$ of $\mathrm{CBr}_{4}-\mathrm{Br}^{-}$compared to $\mathrm{CF}_{3} \mathrm{Br} \cdot \mathrm{Br}^{-}$is found to be determined by polarization as the electrostatic contribution is more favorable for $\mathrm{CF}_{3} \mathrm{Br} \cdot \mathrm{Br}^{-}$. The results of this study demonstrate that the halogen bond can be described accurately by electrostatics and polarization without any need to consider charge transfer.
\end{abstract}

Keywords Halogen bonding $\cdot$ Electrostatic potential $\cdot$ Induction $\cdot$ Charge transfer $\cdot$ Energy decomposition $\cdot$ Sigma-hole

\section{Halogen bonding and the $\sigma$-hole}

According to the recent IUPAC definition: "A halogen bond occurs when there is evidence of a net attractive interaction between an electrophilic region associated with a halogen atom in a molecular entity and a nucleophilic region in another, or the same, molecular entity" [1]. Halogen bonding is a classical interaction in chemistry that has received considerable interest during the last decades due to a large increase of applications within wide areas of chemistry, medicine, and material science [2]. Although the denotation halogen bonding is relatively recent, the first literature reports of halogen bond

This paper belongs to the Topical Collection Tim Clark 70th Birthday Festschrift

Tore Brinck

tore@kth.se

1 Applied Physical Chemistry, Department of Chemistry, CBH, KTH Royal Institute of Technology, SE-100 44 Stockholm, Sweden complexes can be traced to the nineteenth century [3]. Mulliken was a pioneer in the theoretical analysis of halogen bond complexes and interpreted these as donor-acceptor complexes based on spectral analysis [4]. An interpretation that remained the commonly accepted paradigm until the beginning of the twenty-first century. However, already in 1992, Brinck, Murray, and Politzer showed that the halogen bond donating capability of halogenated methanes can be explained by a region of positive surface electrostatic potential at the end (tip) of the halogen atom along the $\mathrm{R}-\mathrm{X}$ axis [5].

In 2005 Clark, Murray, and Politzer, together with Hennemann, introduced the $\sigma$-hole concept to rationalize the positive surface electrostatic potential of the halogen; the $\sigma$ hole was originally viewed as an electron depletion at the halogen tip formed owing to the singly occupied valence $p$ orbital of the halogen in the direction of the $\mathrm{R}-\mathrm{X}$ bond [6] Clark, Murray, and Politzer have remained the main advocates of the $\sigma$-hole concept, continuously revising and developing the theoretical interpretation of the $\sigma$-hole and its importance for halogen bonding [7-12]. Whereas the $\sigma$-hole bonding originally was considered mainly electrostatic in nature, 
Clark, Murray, and Politzer have in recent years emphasized the importance of polarization as a natural and inseparable companion to the electrostatic interaction [9-11]. Furthermore, dispersion is considered as polarization, following Feynman's interpretation [13] based on the HellmannFeynman theorem [10]. Charge transfer, on the other hand, is argued to lack physical significance for noncovalent interactions and to be the result of mathematical modeling, as there is no rigorous approach to separate intra-molecular and intermolecular reorganization of the electron density [10].

Although the $\sigma$-hole interpretation has received considerable acceptance within the scientific community, it has also continuously been challenged by scientist arguing that chargetransfer and orbital interactions must be considered for a complete description of halogen bonding [14-18]. In a recent study, Head-Gordon and coworkers analyzed the potential energy surfaces for a series of complexes of the type $\mathrm{CX}_{3} \mathrm{I} \bullet \mathrm{Y}^{-}$ ( $\mathrm{X}=\mathrm{F}, \mathrm{Cl}, \mathrm{Br}$ and $\mathrm{Y}=\mathrm{F}, \mathrm{Cl}, \mathrm{Br}, \mathrm{I}$ ) by absolutely localized molecular orbitals energy decomposition analysis (ALMO-EDA) [18]. The ALMO-EDA is designed to provide a lower bound to the charge-transfer energy. In this analysis, it was found that for any given $\mathrm{Y}^{-}$the complexation energy of $\mathrm{CX}_{3} \mathrm{I} \bullet \bullet \mathrm{Y}^{-}$decreases in the order $\mathrm{F}, \mathrm{Cl}, \mathrm{Br}$, I, whereas the sum of the Pauli repulsion, electrostatic, and polarization energies increases in the same order. The decrease in the complexation energy was consequently attributed to the charge transfer energy, which in ALMO-EDA is defined as the remaining part of the interaction energy when other energy contributions have been subtracted out.

In a recent article, Clark and Heßelmann responded to the work of Head-Gordon and coworkers by showing that the interaction energy of the entire set of complexes is linearly correlated to the surface electrostatic potential of the $\sigma$-hole, if the surface electrostatic potential is computed from the electron density of the halogen bond donor polarized by a unitary negative charge at the position of the negative halide ion [12]. The correlation coefficient is excellent, $R^{2}=0.994$, demonstrating that the variation in complexation energy is fully reproduced by the polarized surface potential.

The objective of the current work has been to investigate the point charge (PC) approximation in more detail. The use of a PC-model is intriguing in its simplicity and it allows for the exclusion of charge-transfer effects, as there are no electrons that can be transferred. However, it remains to be determined whether such a model can provide consistent results upon larger variations in the chemical environment of the halogen atom, rather than just changing the halogen substituent in $\mathrm{CX}_{3} \mathrm{I}$. In addition, we evaluated the $\mathrm{PC}$ approximation within the classical theory of electrostatics and polarization, as this theory shows that the interaction energy depends upon the cost of polarizing the electron density and therefore cannot be expressed by the electrostatic potential of the polarized charge distribution alone. A further advantage is that the classical theory allows for the interaction energy to be rigorously separated into contributions from electrostatics and polarization.

In this work, we studied a range of halogen bonded complexes of the types; $\mathrm{R}-\mathrm{Br} \bullet \cdot \mathrm{Br}^{-}$where $\mathrm{R}$ is a substituted methyl group, i.e., $\mathrm{R}=\mathrm{CH}_{3}, \mathrm{CH}_{2} \mathrm{NH}_{2}, \mathrm{CH}_{2} \mathrm{~F}, \mathrm{CH}_{2} \mathrm{Br}, \mathrm{CH}_{2} \mathrm{CHO}$, $\mathrm{CH}_{2} \mathrm{CN}, \mathrm{CH}_{2} \mathrm{NO}_{2}, \mathrm{CF}_{2} \mathrm{CN}, \mathrm{CF}_{2} \mathrm{NO}_{2}, \mathrm{CF}_{3}$, and $\mathrm{CBr}_{3}$; and $\mathrm{R}^{\prime}-$ $\mathrm{C} \equiv \mathrm{C}-\mathrm{Br} \cdot \bullet^{-} \mathrm{Br}^{-}$where $\mathrm{R}$ is a substituent, i.e., $\mathrm{R}^{\prime}=\mathrm{H}, \mathrm{NH}_{2}, \mathrm{~F}$, $\mathrm{Br}, \mathrm{CN}, \mathrm{NO}_{2}$, and the aromatic substituents $\mathrm{R}^{\prime}=\mathrm{C}_{6} \mathrm{H}_{5}, \mathrm{C}_{6} \mathrm{~F}_{5}$, and $p-\mathrm{C}_{6} \mathrm{H}_{4} \mathrm{NO}_{2}$. The selection of $\mathrm{R}-\mathrm{Br} \cdot \cdot \mathrm{Br}^{-}$complexes was inspired by the work of Rosokha et al. [15], as they argue that the halogen bond in these types of complexes has a significant contribution from charge transfer due to the interaction of the $\mathrm{Br}$ lone pair with the $\mathrm{C}-\mathrm{Br} \sigma^{*}$-orbital. Complexes of the $\mathrm{R}-$ $\mathrm{Br} \bullet \bullet \mathrm{Br}^{-}$type are expected to behave similarly to $\mathrm{R}-\mathrm{I} \cdot \bullet \cdot \mathrm{Br}^{-}$ complexes, which were studied by Head-Gordon and coworkers, but the former type of complexes is easier to characterize theoretically; $\mathrm{Br}$, in contrast to I, can be modeled without consideration of relativistic effects. We chose to include a group of alkyne halogen bond donors as previous studies have indicated that these generally form stronger complexes than alkyl halogen bond donors, and they exhibit larger substituent effects $[19,20]$. Furthermore, the chosen substituents include both inductive and resonance acceptors, as we hypothesized that the latter type would promote charge transfer more effectively. Despite the efforts to maximize the potential for charge transfer, our results show that the halogen bond interactions of these complexes are governed by electrostatics and polarization and that charge transfer is of negligible importance.

\section{Methods and procedure}

The halogen bonded complexes have been analyzed by full structure optimization using Kohn-Sham density functional theory at the M06-2X/6-311+G(d,p) level. The M06-2X functional is highly accurate for main-group chemistry, including noncovalent interactions and it explicitly accounts for dispersion interactions [21]. It has been evaluated against the halogen bond benchmark data base (XB51) and been shown to provide excellent geometries and energies [22]. The RMSD of M06-2X for interaction energies is $0.43 \mathrm{kcal} \mathrm{mol}^{-1}$, which is much lower than, e.g., MP2 extrapolated to infinite basis set $\left(\mathrm{RMSD}=0.92 \mathrm{kcal} \mathrm{mol}^{-1}\right)$. The $6-311+\mathrm{G}(\mathrm{d}, \mathrm{p})$ basis set used herein is sufficiently flexible and diffuse to reduce the basis set superposition error to acceptable levels. Additional computations have been performed at the same level of theory using a point charge to represent the $\mathrm{Br}^{-}$anion. These computations used the optimized geometries of the halogen bonded complexes, but a negative point charge $(-1 \mathrm{au})$ was placed at the position of $\mathrm{Br}^{-}$. In addition, the electrostatic potential was computed from the unperturbed density, and from the point 
charge perturbed density, of the halogen bond donors in the geometries of the complexes. All computations were performed using the Gaussian 16 suite of software [23].

\section{The classical interaction energy of a point charge (PC)}

The electrostatic potential of an atom or a molecule is rigorously defined by

$V(\mathbf{r})=\sum_{A} \frac{Z_{A}}{\left|\mathbf{R}_{A}-\mathbf{r}\right|}-\int \frac{\rho\left(\mathbf{r}^{\prime}\right) d \mathbf{r}}{\left|\mathbf{r}^{\prime}-\mathbf{r}\right|}$

where $Z_{\mathrm{A}}$ is the charge on nucleus A located at $\mathbf{R}_{A}$, and $\rho(\mathbf{r})$ is the electron density function. $V(\mathbf{r})$ is a real physical observable and can be determined from an experimentally obtained charge distribution obtained by, e.g., diffraction methods. More commonly, $V(\mathbf{r})$ is determined computationally by wavefunction theory or Kohn-Sham density functional theory. In this respect, it should be noted that $V(\mathbf{r})$ is a one-electron property and as such less sensitive to computational level and basis set than, e.g., the electronic energy. The electrostatic interaction energy with a point charge is defined by

$\Delta E_{\mathrm{ES}}^{\mathrm{PC}}=q V\left(\mathbf{r}_{q}\right)$

and corresponds to the energy of the Coulombic interaction between a point charge $q$ located at $\mathbf{r}_{\mathrm{q}}$ and the static (unperturbed) charge distribution of the molecule. It equals the exact interaction energy in the limit of an infinitesimal point charge, as the polarization at this limit is negligible. It is also possible to compute $V(\mathbf{r})$ from a polarized electron density. If $V^{\mathrm{PC}}(\mathbf{r})$ refers to the potential obtained from a density polarized by a point charge $q$ located at $\mathbf{r}_{q}$ then $q V^{\mathrm{PC}}\left(\mathbf{r}_{q}\right)$ is the energy of the Coulombic interaction between $q$ and the polarized charge distribution of the molecule or atom. It must be noted, however, that this is not the same as the total interaction energy, as there is a cost of polarizing, or deforming, the electron density. According to the classical description of polarization, which is based on a linear response to the electric field generated by the point charge, the total interaction energy is given by

$\Delta E^{\mathrm{PC}-\mathrm{Lin}}=1 / 2 q\left[V\left(\mathbf{r}_{q}\right)+V^{\mathrm{PC}}\left(\mathbf{r}_{q}\right)\right]$

The polarization energy, i.e., the classical induction energy, is defined by

$\Delta E_{\mathrm{Pol}}^{\mathrm{PC}-\mathrm{Lin}}=\Delta E^{\mathrm{PC}-\mathrm{Lin}}-\Delta E_{E S}^{\mathrm{PC}}=1 / 2 q\left[V^{\mathrm{PC}}\left(\mathbf{r}_{q}\right)-V\left(\mathbf{r}_{q}\right)\right]$

and the cost of polarizing the electron density is the difference between the total interaction energy and the Coulombic interaction energy of the polarized system

$$
\begin{aligned}
\Delta E_{\rho-\operatorname{def}}^{\mathrm{PC}-\mathrm{Lin}} & =\Delta E^{\mathrm{PC}-\mathrm{Lin}}-q V^{\mathrm{PC}}\left(\mathbf{r}_{q}\right) \\
& =-1 / 2 q\left[V^{\mathrm{PC}}\left(\mathbf{r}_{q}\right)-V\left(\mathbf{r}_{q}\right)\right]=-\Delta E_{\mathrm{Pol}}^{\mathrm{PC}-\mathrm{Lin}}
\end{aligned}
$$

\section{The quantum chemical PC-model of the halogen bond complexes}

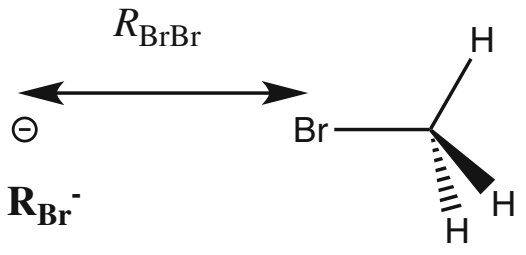

The scheme above shows the point charge model for the interaction of $\mathrm{Br}^{-}$with a halogen bond donor of the type $\mathrm{R}-\mathrm{Br}$. The nuclear geometry of $\mathrm{R}-\mathrm{Br}$ is taken from the full geometry optimization of the complex, and the point charge $\left(q_{\mathrm{Br}}{ }^{-}=-1\right)$ is placed at the position $\left(\mathbf{R}_{\mathrm{Br}}{ }^{-}\right)$of the Br nucleus in the complex. The total interaction energy $\left(\Delta E^{\mathrm{PC}}\right)$ between the point charge and $\mathrm{R}-\mathrm{Br}$ is obtained as the difference in the BornOppenheimer energy with and without the point charge included in the electronic Hamiltonian. It should be noted that the relaxed geometry of $\mathrm{R}-\mathrm{Br}$ in the complex is used for both calculations. The $\Delta E^{\mathrm{PC}}$ can be divided into an electrostatic interaction energy and a polarization (induction) energy

$\Delta E^{\mathrm{PC}}=\Delta E_{\mathrm{ES}}^{\mathrm{PC}}+\Delta E_{\mathrm{Pol}}^{\mathrm{PC}}$

where the electrostatic contribution can be computed directly from the electrostatic potential at $\mathbf{R}_{\mathrm{Br}-}$,

$\Delta E_{\mathrm{ES}}^{\mathrm{PC}}=q_{\mathrm{Br}^{-}} V\left(\mathbf{r}_{q}\right)=-V\left(\mathbf{R}_{\mathrm{Br}^{-}}\right)$

and the polarization energy is given by

$\Delta E_{\mathrm{Pol}}^{\mathrm{PC}}=\Delta E^{\mathrm{PC}}-\Delta E_{\mathrm{ES}}^{\mathrm{PC}}=\Delta E^{\mathrm{PC}}+V\left(\mathbf{R}_{\mathrm{Br}^{-}}\right)$

The energy cost of polarizing the electron density is analogous to Eq. 5 described by

$\Delta E_{\rho-\text { def }}^{\mathrm{PC}}=\Delta E^{\mathrm{PC}}+V^{\mathrm{PC}}\left(\mathbf{R}_{\mathrm{Br}^{-}}\right)$

Furthermore, the polarization is expected to approximatively follow linear response, and thus

$\Delta E^{\mathrm{PC}} \approx-1 / 2\left[V\left(\mathbf{R}_{\mathrm{Br}^{-}}\right)+V^{\mathrm{PC}}\left(\mathbf{R}_{\mathrm{Br}^{-}}\right)\right]$

and

$\Delta E_{\rho-\text { def }}^{\mathrm{PC}} \approx-\Delta E_{\mathrm{Pol}}^{\mathrm{PC}}$

In fact, how well these relationships are fulfilled provides an indication to what extent the system behaves according to classical polarization theory. 
Finally, there is an energy cost of deforming the nuclear geometry of RBr into its geometry in the complex. This term, $\Delta E_{\text {Nuc-def }}$, is simply computed as the difference in the quantum chemical energy (Born-Oppenheimer energy) of $\mathrm{RBr}$ at the two geometries. It should be remembered that the driving force for the deformation is to lower the total interaction energy of the complex.

\section{$\mathrm{PC}$ approximation and the $\mathrm{PES}$ of $\mathrm{CF}_{3} \mathrm{Br} \bullet \cdot \mathrm{Br}^{-}$ and $\mathrm{CBr}_{4}-\mathrm{Br}^{-}$}

We will first analyze the $\mathrm{PC}$ approximation with respect to the potential energy surfaces (PES) of the $\mathrm{CF}_{3} \mathrm{Br}^{*} \cdot \mathrm{Br}^{-}$and $\mathrm{CBr}_{4}-$ $\mathrm{Br}^{-}$complexes along the $\mathrm{Br}-\mathrm{Br}^{-}$distance $(R)$ as shown in Fig. 1 . The relevant energy components at the equilibrium geometry of the complexes are presented in Table 1. Starting with $\mathrm{CF}_{3} \mathrm{Br} \bullet \cdot \mathrm{Br}^{-}$we note that the $\mathrm{PC}$ interaction energy $\left(\Delta E^{\mathrm{PC}}\right)$ is very similar to the full quantum chemical interaction energy $\left(\Delta E_{\text {Int }}\right)$ at long $R$, i.e., distances beyond $5 \AA$. It can be further be noted that at distances longer than twice the equilibrium distance $\left(R>2 R_{\mathrm{eq}}\right)$ the electrostatic interaction energy $\left(\Delta E_{\mathrm{ES}}^{\mathrm{PC}}\right)$ is only marginally higher than $\Delta E^{\mathrm{PC}}$, e.g., $0.37 \mathrm{kcal} \mathrm{mol}^{-1}$ at $R=6.5 \AA$. However, the difference between $\Delta E^{\mathrm{PC}}$ and $\Delta E_{\mathrm{ES}}^{\mathrm{PC}}$, i.e., the polarization/induction energy $\left(\Delta E_{\mathrm{Pol}}^{\mathrm{PC}}\right)$, increases in magnitude as $R$ decreases. At the equilibrium geometry of the complex $\left(R_{\text {eq }}=3.13 \AA\right), \Delta E_{\mathrm{ES}}^{\mathrm{PC}}=-9.61 \mathrm{kcal} \mathrm{mol}^{-1}$ and $\Delta E_{\mathrm{Pol}}^{\mathrm{PC}}=$ $-5.43 \mathrm{kcal} \mathrm{mol}^{-1}$, and thus $\Delta E_{\mathrm{Pol}}^{\mathrm{PC}}$ constitutes $36 \%$ of $\Delta E^{\mathrm{PC}}$.

Returning to the comparison between $\Delta E^{\mathrm{PC}}$ and $\Delta E_{\text {Int }}$, there is a small but significant difference between the two in the region $3.5<R<5 \AA$, with $\Delta E_{\text {Int }}$ being lower by at the most $1.5 \mathrm{kcal} \mathrm{mol}^{-1}(R=3.8 \AA)$. This difference can be attributed to contributions from polarization of $\mathrm{Br}^{-}$and dispersion

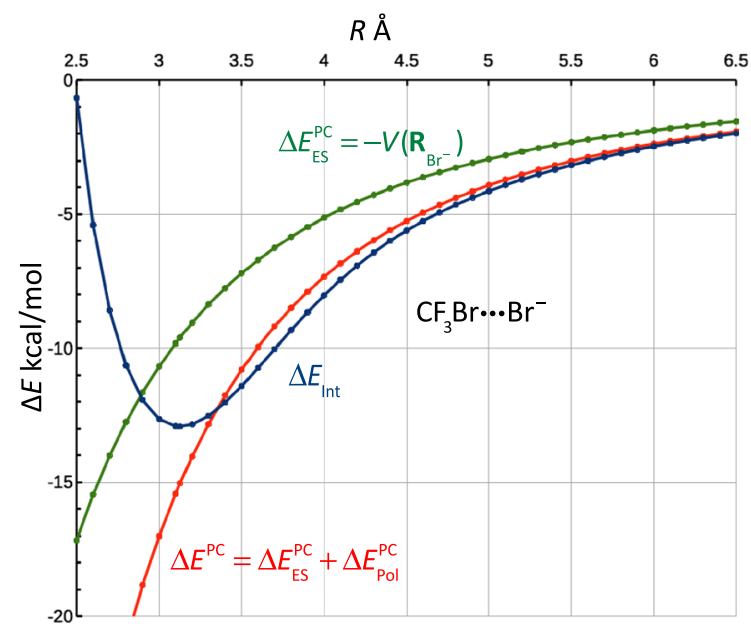

Fig. 1 The full quantum chemical interaction energy $\left(\Delta E_{\text {Int }}\right)$, together with the interaction energy of a point charge $\left(\Delta E^{\mathrm{PC}}\right)$ located at the position of $\mathrm{Br}^{-'}$, and its electrostatic component $\left(\Delta E_{\mathrm{ES}}^{\mathrm{PC}}\right)$, plotted as a interactions, contributions that are short ranged in nature and that are not accounted for by the PC-model. However, at shorter $R, \Delta E_{\text {Int }}$ is beginning to level off, and at $R=3.2 \AA$, $\Delta E^{\mathrm{PC}}$ becomes lower than $\Delta E_{\text {Int. }}$ This is partly an effect of charge penetration; the nuclei of $\mathrm{CF}_{3} \mathrm{Br}$, in particular $\mathrm{Br}$, penetrate inside the electron density distribution of $\mathrm{Br}^{-}$, resulting in a reduced shielding of the nucleus of $\mathrm{Br}^{-}$and higher Coulombic interaction energy [24, 25]. In addition, there is a repulsive contribution to $\Delta E_{\text {Int }}$ due to the Pauli antisymmetry requirement. Neither the charge penetration of $\mathrm{Br}^{-}$nor the Pauli repulsion are accounted for by the PC approximation, and hence the lower $\Delta E^{\mathrm{PC}}$ compared to $\Delta E_{\text {Int }}$ at small $R$. In addition, there is the cost of deforming the structure of $\mathrm{CF}_{3} \mathrm{Br}$ to its geometry in the complex, i.e., $\Delta E_{\mathrm{Nuc}-\text { def }}$, which amounts to $1.1 \mathrm{kcal} \mathrm{mol}^{-1}$ and is missing from $\Delta E^{\mathrm{PC}}$. At the equilibrium geometry, $\Delta E^{\mathrm{PC}}$ and $\Delta E_{\text {Int }}$ differ by $2.1 \mathrm{kcal} \mathrm{mol}^{-1}$, and the values are -15.0 and $-12.9 \mathrm{kcal} \mathrm{mol}^{-1}$, respectively.

When comparing the PES of $\mathrm{CBr}_{4}-\mathrm{Br}^{-}$and $\mathrm{CF}_{3} \mathrm{Br} \bullet \cdot \mathrm{Br}^{-}$, there are similarities but also significant differences in the behavior of the different energy terms. First of all, we note that the former interaction is significantly weaker at long $R$. This is due to a smaller electrostatic contribution to the interaction, i.e., higher $\Delta E_{\mathrm{ES}}^{\mathrm{PC}}$. However, $\Delta E_{\mathrm{Pol}}^{\mathrm{PC}}$ is consistently lower than for

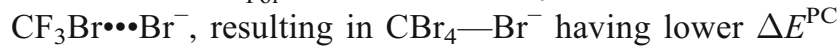
(and $\Delta E_{\text {Int }}$ ) than $\mathrm{CF}_{3} \mathrm{Br} \cdot \cdot \mathrm{Br}^{-}$at shorter distances. Comparing $\Delta E^{\mathrm{PC}}$ and $\Delta E_{\text {Int }}$ of $\mathrm{CBr}_{4}-\mathrm{Br}^{-}$, these are again very similar at long $R$, but diverge in the intermediate region $(3.5<R<5 \AA)$. Compared to $\mathrm{CF}_{3} \mathrm{Br} \cdot \cdot \mathrm{Br}^{-}$, the difference between the two energies in this region is larger, which can be attributed to larger contributions to $\Delta E_{\text {Int }}$ from polarization/induction of $\mathrm{Br}^{-}$and dispersion. Both effects can be attributed to the higher polarizability of $\mathrm{CBr}_{4}$ compared to $\mathrm{CF}_{3} \mathrm{Br}$, which results in a stronger

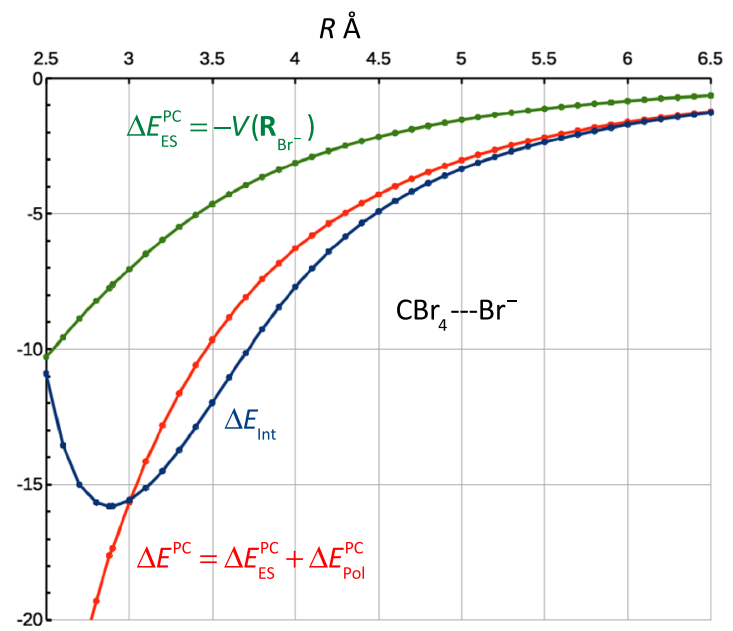

function of of the $\mathrm{Br}-\mathrm{Br}^{-}$distance $(R)$ for the $\mathrm{CF}_{3} \mathrm{Br}^{-} \cdot \mathrm{Br}^{-}$and $\mathrm{CBr}_{4}-$ $\mathrm{Br}^{-}$complexes. Note the much larger contribution from polarization, as defined by the difference $\Delta E_{\mathrm{Pol}}^{\mathrm{PC}}=\Delta E^{\mathrm{PC}}-\Delta E_{\mathrm{ES}}^{\mathrm{PC}}$, in the latter complex 


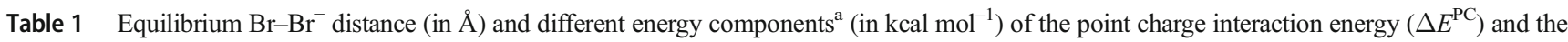
quantum chemical interaction energy $\left(\Delta E_{\text {Int }}\right)$ for the halogen bond complexes

\begin{tabular}{|c|c|c|c|c|c|c|c|}
\hline Complex & $R_{\mathrm{BrBr}}$ & $\Delta E_{\mathrm{ES}}^{\mathrm{PC}}$ & $\Delta E_{\mathrm{Pol}}^{\mathrm{PC}}$ & $\Delta E_{\rho-\operatorname{def}}^{\mathrm{PC}}$ & $\Delta E^{\mathrm{PC}}$ & $\Delta E_{\text {Nuc-def }}$ & $\Delta E_{\text {Int }}$ \\
\hline \multicolumn{8}{|l|}{$\mathrm{R}-\mathrm{Br}, \mathrm{R}=$} \\
\hline $\mathrm{CH}_{2} \mathrm{NH}_{2}$ & 3.45 & 4.2 & -4.6 & 4.4 & -0.5 & 1.0 & 0.0 \\
\hline $\mathrm{CH}_{3}$ & 3.40 & 3.5 & -4.0 & 3.9 & -0.5 & 0.1 & -0.9 \\
\hline $\mathrm{CH}_{2} \mathrm{~F}$ & 3.33 & -0.7 & -4.4 & 4.3 & -5.1 & 0.3 & -4.7 \\
\hline $\mathrm{CH}_{2} \mathrm{Br}$ & 3.23 & -1.7 & -5.6 & 5.4 & -7.3 & 0.4 & -6.6 \\
\hline $\mathrm{CH}_{2} \mathrm{CHO}$ & 3.22 & -2.1 & -5.6 & 5.4 & -7.7 & 0.4 & -7.3 \\
\hline $\mathrm{CH}_{2} \mathrm{CN}$ & 3.12 & -4.6 & -6.2 & 6.0 & -10.8 & 0.5 & -10.2 \\
\hline $\mathrm{CH}_{2} \mathrm{NO}_{2}$ & 3.19 & -6.1 & -5.5 & 5.3 & -11.6 & 0.6 & -10.3 \\
\hline $\mathrm{CF}_{3}$ & 3.13 & -9.6 & -5.4 & 5.2 & -15.0 & 1.1 & -12.9 \\
\hline $\mathrm{CBr}_{3}$ & 2.88 & -7.8 & -9.9 & 9.5 & -17.7 & 1.3 & -15.8 \\
\hline $\mathrm{CF}_{2} \mathrm{CN}$ & 2.97 & -12.1 & -6.9 & 6.6 & -18.9 & 1.0 & -16.8 \\
\hline $\mathrm{CF}_{2} \mathrm{NO}_{2}$ & 2.97 & -14.6 & -7.2 & 6.9 & -21.8 & 1.3 & -19.0 \\
\hline \multicolumn{8}{|c|}{$\mathrm{R}^{\prime}-\mathrm{C} \equiv \mathrm{C}-\mathrm{Br}, \mathrm{R}^{\prime}=$} \\
\hline $\mathrm{NH}_{2}$ & 3.24 & -3.1 & -5.5 & 5.4 & -8.6 & 0.4 & -7.3 \\
\hline $\mathrm{H}$ & 3.20 & -6.8 & -5.4 & 5.3 & -12.2 & 0.2 & -10.8 \\
\hline ar $-\mathrm{C}_{6} \mathrm{H}_{5}$ & 3.18 & -5.6 & -7.0 & 6.8 & -12.6 & 0.2 & -11.0 \\
\hline $\mathrm{F}$ & 3.16 & -8.1 & -5.5 & 5.4 & -13.6 & 0.5 & -11.9 \\
\hline $\mathrm{Br}$ & 3.15 & -8.0 & -6.4 & 6.2 & -14.4 & 0.3 & -12.6 \\
\hline$a r-\mathrm{C}_{6} \mathrm{~F}_{5}$ & 3.10 & -10.8 & -7.5 & 7.4 & -18.4 & 0.4 & -16.0 \\
\hline$p-\mathrm{C}_{6} \mathrm{H}_{4} \mathrm{NO}_{2}$ & 3.11 & -11.0 & -7.7 & 7.6 & -18.7 & 0.4 & -16.4 \\
\hline $\mathrm{CN}$ & 3.05 & -16.0 & -7.2 & 7.0 & -23.2 & 0.4 & -20.5 \\
\hline $\mathrm{NO}_{2}$ & 3.02 & -17.6 & -7.2 & 7.1 & -24.8 & 0.8 & -21.7 \\
\hline
\end{tabular}

${ }^{a}$ The different energy components are defined in the main text. Energies are here reported with only one decimal place to increase the readability, but energies with two decimal places are used for plots and linear regressions

dispersion interaction and a higher (induced) dipole moment of $\mathrm{CBr}_{4}$; the induction energy resulting from polarization of $\mathrm{Br}^{-}$is quadratically dependent on the effective dipole moment of the halogen bond donor. The dipole moment of the PC polarized halogen bond donor at the equilibrium geometry of the complex is 3.06 and 3.56 Debye for $\mathrm{CF}_{3} \mathrm{Br}$ and $\mathrm{CBr}_{4}$, respectively. Potentially, one could also envision a larger charge-transfer contribution to the $\mathrm{CBr}_{4}-\mathrm{Br}^{-}$complex, but, as we will discuss later, we find no indication for such a term to be significant in these types of complexes.

At the equilibrium geometry $(R=2.88 \AA)$ of $\mathrm{CBr}_{4}-\mathrm{Br}^{-}$, $\Delta E^{\mathrm{PC}}$ is $1.9 \mathrm{kcal} \mathrm{mol}^{-1}$ lower than $\Delta E_{\mathrm{Int}}$. This energy difference is very similar to the corresponding difference $\left(2.1 \mathrm{kcal} \mathrm{mol}^{-1}\right)$ for $\mathrm{CF}_{3} \mathrm{Br} \cdots \mathrm{Br}^{-}$. Thus, despite that the $\mathrm{PC}-$ model is approximate and only considers electrostatics and polarization, it reproduces the quantum chemical energy difference between the complexes; $\Delta E^{\mathrm{PC}}$ and $\Delta E_{\text {Int }}$ of $\mathrm{CBr}_{4}-\mathrm{Br}^{-}$are 17.6 and $15.8 \mathrm{kcal} \mathrm{mol}^{-1}$, respectively, whereas the corresponding energies of $\mathrm{CF}_{3} \mathrm{Br} \bullet \bullet \mathrm{Br}^{-}$are -15.0 and $-12.9 \mathrm{kcal} \mathrm{mol}^{-1}$. The results of the PC-model show that the lower complexation energy of $\mathrm{CBr}_{4}-$ $\mathrm{Br}^{-}$is entirely due to polarization $\left(\Delta E_{\mathrm{Pol}}^{\mathrm{PC}}=-9.9 \mathrm{kcal} \mathrm{mol}^{-1}\right)$, as the electrostatic interaction $\left(\Delta E_{\mathrm{ES}}^{\mathrm{PC}}=-7.7 \mathrm{kcal} \mathrm{mol}^{-1}\right)$ is less favorable than for $\mathrm{CF}_{3} \mathrm{Br} \bullet \cdot \mathrm{Br}^{-}\left(\Delta E_{\mathrm{ES}}^{\mathrm{PC}}=-9.61\right)$. In the case of $\mathrm{CBr}_{4}-\mathrm{Br}^{-}, \Delta E_{\mathrm{Pol}}^{\mathrm{PC}}$ comprises $56 \%$ of $\Delta E^{\mathrm{PC}}$, which is much higher than the $36 \%$ contribution in $\mathrm{CF}_{3} \mathrm{Br}^{\circ} \cdot \mathrm{Br}^{-}$. These results can be compared to the EDA results of Head-Gordon and coworkers for the analogous $\mathrm{CF}_{3}\left[\cdots \mathrm{Br}^{-}\right.$and $\mathrm{CBr}_{3}\left[\cdots \mathrm{Br}^{-}\right.$complexes [17]. They also found that the substitution of $\mathrm{CF}_{3}$ by $\mathrm{CBr}_{3}$ leads to a significant decrease in $\Delta E_{\text {Int }}$. However, whereas Head-Gordon and coworkers attributed this result to charge transfer, our computations unambiguously show that the lower $\Delta E_{\text {Int }}$ of the brominated compound is a polarization effect.

\section{Electrostatics and polarization determine the halogen bond energy}

In Table 1 we list the different energy components of the PCmodel together with the full quantum chemical interaction energy $\left(\Delta E_{\text {Int }}\right)$ for the entire set of halogen bonded complexes. Optimized geometries of selected complexes are presented in Fig. 2. We first note that the PC-model interaction energy generally is similar, albeit slightly larger, in magnitude to the 
Fig. 2 Geometries of some representative complexes computed at the M06-2X/6-311+ $\mathrm{G}(\mathrm{d}, \mathrm{p})$ level of theory. Relevant interatomic distances are given in Angstrom
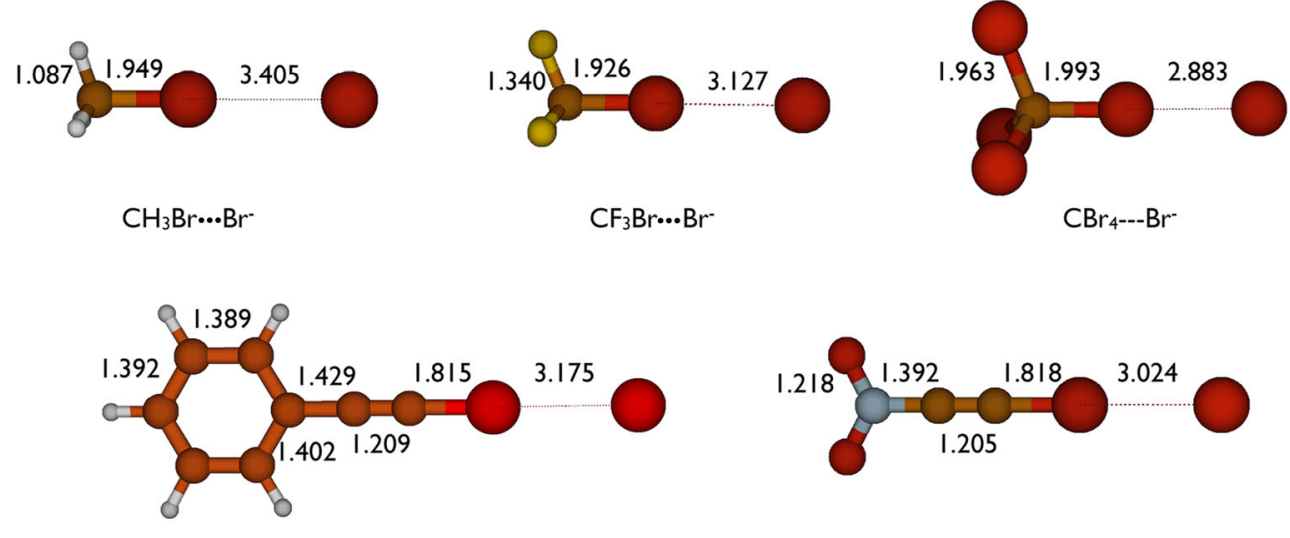

ar- $\mathrm{C}_{6} \mathrm{H}_{5} \mathrm{C} \equiv \mathrm{CBr} . . . \mathrm{Br}^{-}$

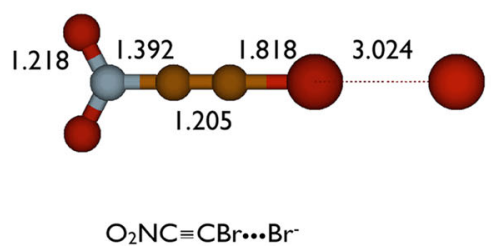

quantum chemical interaction energy $\left(\Delta E_{\text {Int }}\right)$ over the entire data set. There is an excellent linear relationship $\Delta E_{\mathrm{Int}}=$ $0.88 \Delta E^{\mathrm{PC}}$ with a correlation coefficient of $R^{2}=0.9995$ and standard error in predicted $\Delta E_{\mathrm{Int}}$ of $0.29 \mathrm{kcal} \mathrm{mol}^{-1}$, as shown in Fig. 3. It should be remembered that $\Delta E^{\mathrm{PC}}$ does not consider the cost of deforming the halogen bond donor to its geometry in the complex, and if $\Delta E_{\mathrm{Nuc}-\text { def }}$ is added to $\Delta E^{\mathrm{PC}}$, the proportionality constant increases to 0.92 and $R^{2}$ decreases only marginally to $R^{2}=0.9990$.

The almost perfect correlation together with the slope being close to unity and the zero intercept show that the PC-model is able to reproduce the halogen bond interaction energy surprisingly well. The high quality of the correlation is remarkable considering that there are large variations in the chemical environment of the halogen bond donating $\mathrm{Br}$. As indicated in the discussion of the PES of $\mathrm{CF}_{3} \mathrm{Br} \cdot \mathrm{Br}^{-}$above, there are energy contributions to $\Delta E_{\mathrm{Int}}$ that are missing from $\Delta E^{\mathrm{PC}}$ due to the $\mathrm{PC}$ approximation of $\mathrm{Br}^{-}$. However, the correlation equation indicates that the sum of these contributions is a positive energy contribution that varies proportionality to $\Delta E_{\text {Int }}$ and typically amounts to around $8 \%$ of $\Delta E_{\text {Int }}$. Thus, our results show that electrostatics and polarization are sufficient to describe the variation in the halogen bond energy, and that charge transfer only has a marginal influence, at most, on the strength of the halogen bond.

Table 1 also lists the electrostatic interaction energy $\left(\Delta E_{\mathrm{ES}}^{\mathrm{PC}}\right)$ and the po larization/induction energy $\left(\Delta E_{\mathrm{Pol}}^{\mathrm{PC}}\right)$ for the entire data set, where the former is computed from the electrostatic potential at the position of $\mathrm{Br}^{-}$and the latter using Eq. (7). Interestingly, the two components are on average of similar size; however, whereas $\Delta E_{\mathrm{ES}}^{\mathrm{PC}}$ varies between 4 and $-18 \mathrm{kcal} \mathrm{mol}^{-1}, \Delta E_{\mathrm{Pol}}^{\mathrm{PC}}$ varies less, and lies with the exception of $\mathrm{CBr}_{4}-\mathrm{Br}^{-}\left(-9.9 \mathrm{kcal} \mathrm{mol}^{-1}\right)$ in the range of -4 to $-8 \mathrm{kcal} \mathrm{mol}^{-1}$. Figure 3 shows that there is a good linear correlation between $\Delta E_{\mathrm{Int}}$ and $\Delta E_{\mathrm{ES}}^{\mathrm{PC}}$ $\left(\Delta E_{\mathrm{Int}}=1.00 \Delta E_{\mathrm{ES}}^{\mathrm{PC}}-4.7\right)$ with an $R^{2}=0.973$. On the basis of this relationship, solely, one could easily make the interpretation that the interaction energy is dominated by electrostatics and has a nearly constant contribution from polarization of around $-5 \mathrm{kcal} \mathrm{mol}^{-1}$. However, the rationale for the correlation is not that the polarization contribution is nearly constant, as is obvious from Table 1, but that there is, when $\mathrm{CBr}_{4}$ is excluded, a (weak) linear
Fig. 3 The graph to the left shows the excellent correlation between $\Delta E_{\mathrm{Int}}$ and $\Delta E^{\mathrm{PC}}$ for the entire data set of complexes of the types $\mathrm{R}-\mathrm{Br} \cdot \bullet \mathrm{Br}^{-}$and $\mathrm{R}^{\prime}-\mathrm{C} \equiv \mathrm{C}-$ $\mathrm{Br} \bullet \cdot \mathrm{Br}^{-}$. The graph to the right shows the corresponding correlation between $\Delta E_{\mathrm{Int}}$ and $\Delta E_{\mathrm{ES}}^{\mathrm{PC}}$, where $\Delta E_{\mathrm{ES}}^{\mathrm{PC}}$ is computed from the electrostatic potential at the position of the $\mathrm{Br}^{-}$. The $\mathrm{CF}_{3} \mathrm{Br}-\mathrm{Br}^{-}$and $\mathrm{CBr}_{4}-\mathrm{Br}^{-}$ complexes deviate the most from the correlation and their positions are indicated
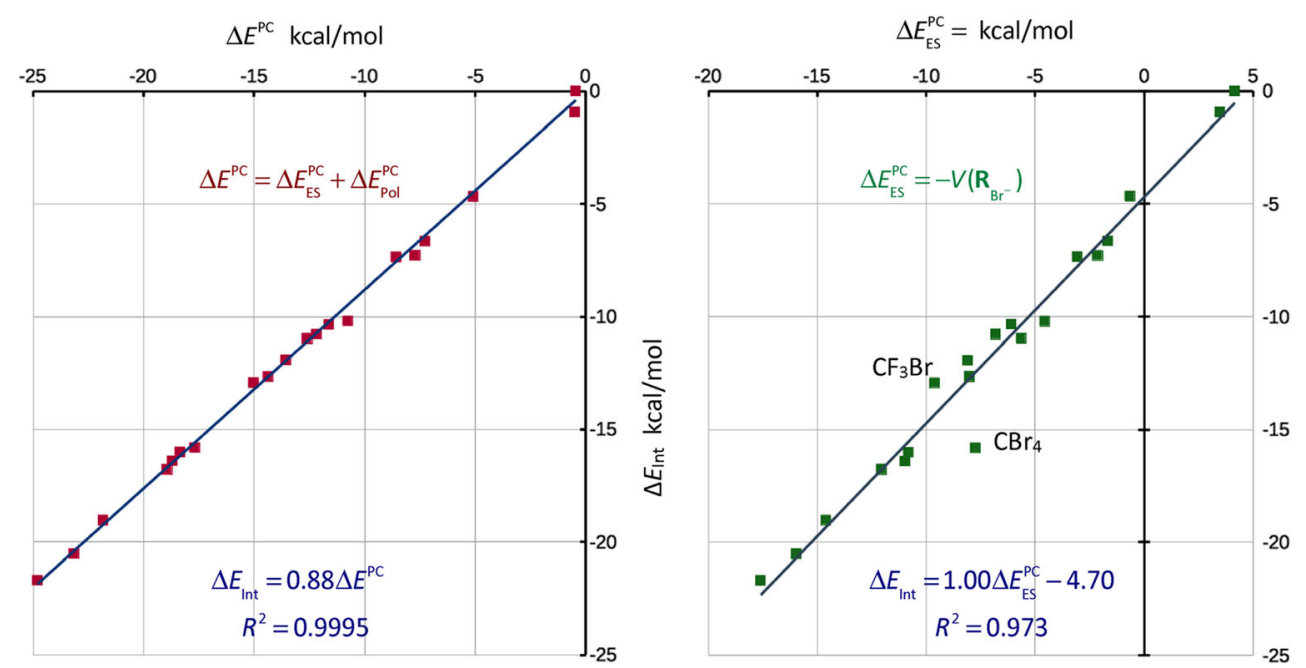
correlation between $\Delta E_{\mathrm{Pol}}^{\mathrm{PC}}$ and $\Delta E_{\mathrm{ES}}^{\mathrm{PC}}$ with an $R^{2}=0.68$. This correlation can partly be explained by that a stronger interaction leads to a shorter $\mathrm{Br} \cdots \mathrm{Br}$ distance, which lowers $\Delta E_{\mathrm{Pol}}^{\mathrm{PC}}$ due to the strong distance dependence of the polarization term. As an example, the weakest complex $\left(\mathrm{NH}_{2} \mathrm{CH}_{2} \mathrm{Br} \bullet \cdot \mathrm{Br}^{-}\right)$has a $\mathrm{Br}-\mathrm{Br}$ distance of $3.45 \AA$ and the strongest $\left(\mathrm{NO}_{2}-\mathrm{C} \equiv \mathrm{C}-\mathrm{Br} \cdot \cdot \mathrm{Br}^{-}\right)$a distance of $3.02 \AA$. However, it should also be recognized that polarization reduces the electron density on the interacting $\mathrm{Br}$ and allows for a closer approach of the $\mathrm{Br}^{-}$; an example of this effect is the very short $\mathrm{Br} \cdots \mathrm{Br}$ distance $(2.88 \AA)$ in $\mathrm{CBr}_{4}-\mathrm{Br}^{-}$, which also is the complex that has the lowest $\Delta E_{\mathrm{Pol}}^{\mathrm{PC}}$ of $-9.9 \mathrm{kcal} \mathrm{mol}^{-1}$.

When we analyze the data for the substituted methyl bromide $(\mathrm{R}-\mathrm{Br})$ donors, there seems to be a general trend that $\Delta$ $E_{\mathrm{ES}}^{\mathrm{PC}}$ is determined by the sum of the electron-withdrawing capacities of the substituents, i.e., substituents like F, CN, and $\mathrm{NO}_{2}$ reduce $\Delta E_{\mathrm{ES}}^{\mathrm{PC}}$ in that order. The $\Delta E_{\mathrm{ES}}^{\mathrm{PC}}$ of the monosubstituted systems follows the same order as the Hammet $\sigma_{p}$ constant. On the other hand, $\Delta E_{\mathrm{Pol}}^{\mathrm{PC}}$ decreases with increasing polarizability of the substituents, i.e., in the order $\mathrm{H} \approx \mathrm{F}<\mathrm{NH}_{2}<\mathrm{CN}<\mathrm{NO}_{2}<\mathrm{Br}$. Although, it may seem trivial that $\Delta E_{\mathrm{Pol}}^{\mathrm{PC}}$ should follow the polarizability of the substituents, the effect is much larger than would be expected from a through-space interaction, and this large substituent effect is a consequence of the polarization being mediated by the covalent bonds. In the case of $\mathrm{CBr}_{4}-\mathrm{Br}^{-}$, the substituent effect on $\Delta E_{\mathrm{Pol}}^{\mathrm{PC}}$ is larger than anticipated based on an additive contribution from the $\mathrm{Br}$ substituents. This can be attributed to the anomeric effect, which is present when several halogens of the same type are bonded to a carbon, and has been described by Clark and coworkers $[12,26]$.

We now turn to the data of the acetylenic $\mathrm{Br}$ donors, i.e., the complexes of the type $\mathrm{R}^{\prime}-\mathrm{C} \equiv \mathrm{C}-\mathrm{Br}$. It can first be noted that the electrostatic interaction in general is more favored $\left(\Delta E_{\mathrm{ES}}^{\mathrm{PC}}\right.$ is much lower) in comparison with the $\mathrm{R}-\mathrm{Br}$ donors. This shows that the $-\mathrm{C} \equiv \mathrm{C}$ - functionality in itself has a strong electron withdrawing effect. This effect is further augmented by the substituent due to resonance interactions. Resonance electron acceptors generally have a similar quantitative effect on the $\Delta E_{\mathrm{ES}}^{\mathrm{PC}}$ as the same substituent on the $\mathrm{R}-\mathrm{Br}$ donors, e.g., a $\mathrm{NO}_{2}$ group lowers $\Delta E_{\mathrm{ES}}^{\mathrm{PC}}$ by around $10 \mathrm{kcal} \mathrm{mol}^{-1}$ in both systems. Another example of the importance of resonance is the lower $\Delta E_{\mathrm{ES}}^{\mathrm{PC}}$ of the $p$ $\mathrm{C}_{6} \mathrm{H}_{4} \mathrm{NO}_{2}$ substituent compared to a plain phenyl $\left(\mathrm{C}_{6} \mathrm{H}_{5}\right)$ group. However, the effect of the $\mathrm{NO}_{2}$ is only $5 \mathrm{kcal} \mathrm{mol}^{-1}$ and thus half of the effect of an $\mathrm{NO}_{2}$ attached directly to $-\mathrm{C} \equiv \mathrm{C}-\mathrm{Br}$. In general, the $\Delta E_{\mathrm{Pol}}^{\mathrm{PC}}$ values are lower compared to the corresponding values for the $\mathrm{R}-\mathrm{Br}$ donors. This can mainly be attributed to the $\mathrm{R}-\mathrm{C} \equiv \mathrm{C}-\mathrm{Br}$ complexes being more stable and having shorter $\mathrm{Br}-\mathrm{Br}$ distances due to the stronger electrostatic interaction. However, the substituent effects on $\Delta E_{\mathrm{Pol}}^{\mathrm{PC}}$ are similar in the two types of complexes, with $\Delta E_{\mathrm{Pol}}^{\mathrm{PC}}$ decreasing with increasing polarizability of the substituent. Also here, we find that the substituent effect on $\Delta E_{\mathrm{Pol}}^{\mathrm{PC}}$ is mediated via the covalent bonds, and for the $\mathrm{R}^{\prime}-\mathrm{C} \equiv \mathrm{C}-\mathrm{Br}$ complexes the bond-mediation is enhanced because of the conjugation.

In Table 1, we also list the density deformation energies, $\Delta E_{\rho \text {-def }}^{\mathrm{PC}}$, and the values follow linear response closely, i.e., $\Delta E_{\rho-\operatorname{def}}^{\mathrm{PC}} \simeq-\Delta E_{\mathrm{Pol}}^{\mathrm{PC}}$. This supports the interpretation that these interactions are governed by classical electrostatics and polarization. In general, the $\Delta E_{\rho \text {-def }}^{\mathrm{PC}}$ values are around $0.2 \mathrm{kcal}$ $\mathrm{mol}^{-1}$ lower than the values that would correspond to an exact linear response behavior. This may seem surprising, as nonlinear contributions to the polarization are expected to lead to $\Delta E_{\rho \text {-def }}^{\mathrm{PC}}>-\Delta E_{\mathrm{Pol}}^{\mathrm{PC}}$. However, there is also an energy cost ( $\left.\Delta E_{\mathrm{Nuc}-\text { def }}\right)$ for deforming the geometry of halogen bond donor to its geometry in the complex, and it can be expected that this deformation facilitates the polarization of the halogen bond donor and lowers $\Delta E_{\mathrm{Pol}}^{\mathrm{PC}}$.

Finally, we turn to the nuclear deformation energy $\left(\Delta E_{\mathrm{Nuc}}\right.$ ${ }_{-\mathrm{def}}$ ) of the complexes, which varies between 0.1 and $1.3 \mathrm{kcal}$ $\mathrm{mol}^{-1}$. Although, it is difficult to fully rationalize the variation of this quantity, some trends can be observed. First of all, we note, following the discussion of $\Delta E_{\rho \text {-def }}^{\mathrm{PC}}$ from above, that those complexes which have the largest $\Delta E_{\mathrm{Nuc}-\text { def }}$ also deviate the most from $\Delta E_{\rho \text {-def }}^{\mathrm{PC}}=-\Delta E_{\mathrm{Pol}}^{\mathrm{PC}}$. Thus, this supports the hypothesis that a significant driving force for the nuclear deformation is to facilitate polarization and thereby maximize the Coulombic interaction between $\mathrm{Br}^{-}$and the halogen bond donor. Secondly, some substituents, e.g., halogens, $\mathrm{NH}_{2}$, and $\mathrm{NO}_{2}$, generate larger $\Delta E_{\mathrm{Nuc}-\text { def }}$ values than others, e.g., aromatic substituents and $\mathrm{H}$. Thirdly, the $\mathrm{R}-\mathrm{Br} \bullet \cdot \mathrm{Br}^{-}$complexes generally have higher values than the corresponding $\mathrm{R}^{\prime}$ $\mathrm{C} \equiv \mathrm{C}-\mathrm{Br} \bullet \cdot \mathrm{Br}^{-}$complexes. However, even though the variation in $\Delta E_{\mathrm{Nuc}-\mathrm{def}}$ is significant, the magnitude of $\Delta E_{\mathrm{Nuc}-\text { def }}$ is generally small compared to the total interaction energy. This can be seen as a confirmation of the noncovalent character of these complexes, as it can be expected that a significant covalent contribution to the interactions would be accompanied with a larger $\Delta E_{\mathrm{Nuc}-\text { def. }}$

\section{Summary and concluding discussion}

In this article, we found that the PC-model accurately describes the variations of the halogen bond interaction energy for a diverse group of halogen bond donors and their complexes with $\mathrm{Br}^{-}$. The analysis of the PES of $\mathrm{CBr}_{4}-\mathrm{Br}^{-}$and $\mathrm{CF}_{3} \mathrm{Br} \cdot \mathrm{Br}^{-}$ shows that $\Delta E_{\text {Int }}$ and $\Delta E^{\mathrm{PC}}$ are very similar at $\mathrm{Br}-\mathrm{Br}^{-}$distances $(R)$ larger than twice the equilibrium distance $\left(R_{\mathrm{eq}}\right)$. In the region $1.8 R_{\mathrm{eq}}>R>1.1 R_{\mathrm{eq}}, \Delta E_{\mathrm{Int}}$ is slightly lower than $\Delta E^{\mathrm{PC}}$ due to energy contributions from polarization of $\mathrm{Br}^{-}$and 
dispersion. At $R<1.1 R_{\mathrm{eq}}, \Delta E_{\text {Int }}$ begins to level off because of increasing charge penetration and Pauli repulsion. At $R_{\text {eq }}$, the sum of the four energy contributions is a positive energy contribution that typically amounts to around $8 \%$ of $\Delta E_{\text {Int. The }}$ remaining part of $\Delta E_{\text {Int }}$ is determined by $\Delta E^{\mathrm{PC}}$ with the exception of a small contribution from $\Delta E_{\text {Nuc-def }}$. This is demonstrated by an excellent linear relationship $\left(R^{2}=0.999\right)$ with a slope of 0.92 , and a zero intercept, between $\Delta E_{\text {Int }}$ and $\left(\Delta E^{\mathrm{PC}}+\Delta E_{\mathrm{Nuc}}\right.$ -def) for the entire group of halogen bond donors. It should be remembered that charge transfer is completely absent from the PC-model, as there are no electrons than can be transferred to the halogen bond donor. Thus, the results of this study strongly indicate that charge transfer is of negligible importance for halogen bonding.

The analysis of halogen bonding interaction using the PC approximation has the added advantage that the interaction energy can be rigorously separated into electrostatics and polarization. Our results emphasize the important role of polarization in halogen bonding. Within the data set, $\Delta E_{\mathrm{ES}}^{\mathrm{PC}}$ varies between 4 and $-18 \mathrm{kcal} \mathrm{mol}^{-1}$, whereas $\Delta E_{\mathrm{Pol}}^{\mathrm{PC}}$ varies between -4 and $-10 \mathrm{kcal} \mathrm{mol}^{-1}$. In six out of 20 complexes, polarization contributes more strongly than electrostatics to the strength of the halogen bond, i.e., $\Delta E_{\mathrm{Pol}}^{\mathrm{PC}}<\Delta E_{\mathrm{ES}}^{\mathrm{PC}}$, and two of these would be unbound without polarization. The analysis further shows that the generally large polarization effect of the studied complexes cannot solely be attributed to the large polarizability of the $\mathrm{Br}$ atom, as the polarization is found to be bond-mediated and strongly dependent on the polarizability of the substituents; this effect is particularly pronounced for the $\mathrm{R}^{\prime}-\mathrm{C} \equiv \mathrm{C}-\mathrm{Br}$ compounds where the bond-mediated polarization is found to be enhanced due to the conjugation. The very low $\Delta E_{\mathrm{Pol}}^{\mathrm{PC}}(-9.9 \mathrm{kcal}$ $\mathrm{mol}^{-1}$ ) of $\mathrm{CBr}_{4}-\mathrm{Br}^{-}$is partly attributed to the anomeric effect that comes from having several $\mathrm{Br}$ bonded to the same C. However, despite the resonance enhanced substituent effects on $\Delta E_{\mathrm{Pol}}^{\mathrm{PC}}$, we found $\Delta E_{\mathrm{Pol}}^{\mathrm{PC}}$ to follow classical polarization with a linear response behavior with respect to the electric field.

We have shown that the difference in $\Delta E_{\text {Int }}$ between the $\mathrm{CF}_{3} \mathrm{Br} \cdot \cdot \mathrm{Br}^{-}$and $\mathrm{CBr}_{4}-\mathrm{Br}^{-}$complexes can be unambiguously rationalized in terms of the much lower $\Delta$ $E_{\text {Pol }}^{\mathrm{PC}}$ of the latter. This is in sharp contrast to the results of Head-Gordon and coworkers on the analogues $\mathrm{CF}_{3} \mathrm{I} \cdots \mathrm{Br}^{-}$and $\mathrm{CBr}_{3} \mathrm{I} \cdots \mathrm{Br}^{-}$complexes; they found the stronger interaction of the $\mathrm{CF}_{3}$ substituted compound to be the result of a lower charge transfer energy [18]. We can only speculate on the reasons for the discrepancy between the results. It should be noted, however, that in the energy decomposition analysis (EDA) used by Head-Gordon the charge transfer energy is computed as the remaining part of the interaction energy when all other components have been subtracted out. Thus, in the hypothetical case that the EDA is not able to completely describe the polarization effect, the missing part of the polarization energy will end up as a contribution to the charge transfer energy. Another reason for the discrepancy could potentially be that the $\mathrm{CX}_{3}\left[\cdots \mathrm{Br}^{-}\right.$ complexes are very different in their behavior from the $\mathrm{CX}_{3} \mathrm{Br} \cdots \mathrm{Br}^{-}$complexes. However, a preliminary analysis using the PC-model confirms that the lower $\Delta E_{\text {Int }}$ of $\mathrm{CBr}_{3} \mathrm{I} \cdots \cdot \mathrm{Br}^{-}$compared to $\mathrm{CF}_{3} \mathrm{I} \cdots \mathrm{Br}^{-}$is an effect of the stronger polarization in the former complex.

We would also like to comment on the fact that Clark and Heßelmann in their study [12] were able to correlate $\Delta E_{\text {Int }}$ with the surface electrostatic potential maximum obtained from the polarized density alone, whereas Eq. 3 shows that the (unpolarized) electrostatic potential and the polarized potential contribute equally by a factor of 0.5 to the interaction energy. The reason for the successful correlation is probably the relatively small variation in the surface electrostatic potential maximum among the studied halogen bond donors in their study, and thus it is likely that the influence of the (average) electrostatic potential is accounted for by the intercept. It is indeed noteworthy that the slope of 0.43 in front of the polarized potential in the Clark and Heßelmann study is very similar to our proportionality constant of 0.88 , from the $\Delta E_{\text {Int }}$ and $\Delta E^{\mathrm{PC}}$ correlation, multiplied by the factor 0.5 .

Finally, we would like to emphasize the advantage of using simple and at the same time physically relevant models when analyzing intermolecular interactions. In this study, charge transfer could be ruled out, as the PC-model accurately reproduces the halogen bond energy without having electrons that can be transferred. Furthermore, we were able to rigorously separate electrostatics from polarization and thereby demonstrate the high importance of polarization for the halogen bond. In an upcoming study we intend to use the same approach to investigate the character of the hydrogen bond to shed light upon the differences and similarities of halogen and hydrogen bonding.

Acknowledgments We would like to thank Tim Clark and his coauthors Jane Murray and Peter Politzer for continuously challenging our thinking and understanding of the halogen bond and intermolecular interactions. The original goal of this study was to demonstrate the importance of charge transfer for halogen bonding, but the results proved our hypothesis wrong. It feels appropriate to cite Newton, if I have seen further it is by standing on the shoulders of Giants.

Financial support of this study has been provided by the VR (Swedish Research Council), and computational time by the Swedish National Infrastructure for Computing (SNIC) at the National Supercomputer Centre in Linköping University as well as at the PDC Centre for High Performance Computing (PDC-HPC).

Open Access This article is distributed under the terms of the Creative Commons Attribution 4.0 International License (http:// creativecommons.org/licenses/by/4.0/), which permits unrestricted use, distribution, and reproduction in any medium, provided you give appropriate credit to the original author(s) and the source, provide a link to the Creative Commons license, and indicate if changes were made. 


\section{References}

1. Desiraju GR, Ho PS, Kloo L, Legon AC, Marquardt R, Metrangolo P, Politzer P, Resnati G, Rissanen K (2013) Definition of the halogen bond (IUPAC recommendations 2013). Pure Appl Chem 85: $1711-1713$

2. Cavallo G, Metrangolo P, Milani R, Pilati T, Priimagi A, Resnati G, Terraneo G (2016) The halogen bond. Chem Rev 116:2478-2601

3. Guthrie F (1863) XXVIII. On the iodide of iodammonium. J Chem Soc 16:239-244

4. Mulliken RS (1950) Structures of complexes formed by halogen molecules with aromatic and with oxygenated solvents 1 . J Am Chem Soc 72:600-608

5. Brinck T, Murray J, Politzer P (1992) Surface electrostatic potentials of halogenated methanes as indicators of directional intermolecular interactions. Int J Quant Chem 44:57-64

6. Clark T, Hennemann M, Murray JS, Politzer P (2007) Halogen bonding: the sigma-hole. J Mol Model 13:291-296

7. Politzer P, Murray JS, Clark T (2010) Halogen bonding: an electrostatically-driven highly directional noncovalent interaction. Phys Chem Chem Phys 12:7748-7757

8. Politzer P, Murray JS, Clark T (2013) Halogen bonding and other $\sigma$-hole interactions: a perspective. Phys Chem Chem Phys 15: 11178-11189

9. Clark T, Politzer P, Murray JS (2015) Correct electrostatic treatment of noncovalent interactions: the importance of polarization. WIREs Comput Mol Sci 5:169-177

10. Politzer P, Murray JS, Clark T (2015) Mathematical modeling and physical reality in noncovalent interactions. J Mol Model 21:21-52

11. Politzer P, Murray JS, Clark T, Resnati G (2017) The $\sigma$-hole revisited. Phys Chem Chem Phys 19:32166-32178

12. Clark T, Heßelmann A (2018) The coulombic $\sigma$-hole model describes bonding in $\mathrm{CX} 3 \mathrm{I} \cdots \mathrm{Y}^{-}$complexes completely. Phys Chem Chem Phys 20:22849-22855

13. Feynman RP (1939) Forces in molecules. Phys Rev 56:340

14. Huber SM, Jimenez-Izal E, Ugalde JM, Infante I (2012) Unexpected trends in halogen-bond based noncovalent adducts. Chem Commun 48:7708-7710

15. Rosokha SV, Stern CL, Ritzert JT (2013) Experimental and computational probes of the nature of halogen bonding: complexes of bromine-containing molecules with bromide anions. Chem Eur J 19:8774-8788

16. Mitoraj MP, Michalak A (2013) Theoretical description of halogen bonding - an insight based on the natural orbitals for chemical valence combined with the extended-transition-state method (ETS-NOCV). J Mol Model 19:4681-4688
17. Wang C, Danovich D, Mo Y, Shaik S (2014) On the nature of the halogen bond. J Chem Theory Comput 10:3726-3737

18. Thirman J, Engelage E, Huber SM, Head-Gordon M (2018) Characterizing the interplay of pauli repulsion, electrostatics, dispersion and charge transfer in halogen bonding with energy decomposition analysis. Phys Chem Chem Phys 20:905-915

19. Beale TM, Chudzinski MG, Sarwar MG, Taylor MS (2013) Halogen bonding in solution: thermodynamics and applications. Chem Soc Rev 42:1667-1680

20. Matsuzawa A, Takeuchi S, Sugita K (2016) Iodoalkyne-based catalyst-mediated activation of thioamides through halogen bonding. Chem Asian J 11:2863-2866

21. Zhao Y, Truhlar DG (2008) The M06 suite of density functionals for main group thermochemistry, thermochemical kinetics, noncovalent interactions, excited states, and transition elements: two new functionals and systematic testing of four m06-class functionals and 12 other functionals. Theor Chem Accounts 120:215-241

22. Kozuch S, Martin JML (2013) Halogen bonds: benchmarks and theoretical analysis. J Chem Theory Comput 9:1918-1931

23. Frisch MJ, Trucks GW, Schlegel HB, Scuseria GE, Robb MA, Cheeseman JR, Scalmani G, Barone V, Petersson GA, Nakatsuji H, Li X, Caricato M, Marenich AV, Bloino J, Janesko BG, Gomperts R, Mennucci B, Hratchian HP, Ortiz JV, Izmaylov AF, Sonnenberg JL, Williams, Ding F, Lipparini F, Egidi F, Goings J, Peng B, Petrone A, Henderson T, Ranasinghe D, Zakrzewski VG, Gao J, Rega N, Zheng G, Liang W, Hada M, Ehara M, Toyota K, Fukuda R, Hasegawa J, Ishida M, Nakajima T, Honda Y, Kitao O, Nakai H, Vreven T, Throssell K, Montgomery Jr JA, Peralta JE, Ogliaro F, Bearpark MJ, Heyd JJ, Brothers EN, Kudin KN, Staroverov VN, Keith TA, Kobayashi R, Normand J, Raghavachari K, Rendell AP, Burant JC, Iyengar SS, Tomasi J, Cossi M, Millam JM, Klene M, Adamo C, Cammi R, Ochterski JW, Martin RL, Morokuma K, Farkas O, Foresman JB, Fox DJ (2016) Gaussian 16, rev. B.01. Gaussian Inc., Wallingford

24. Sen KD, Politzer P (1989) Characteristic features of the electrostatic potentials of singly negative monoatomic ions. J Chem Phys 90: $4370-4372$

25. Wang B, Truhlar DG (2010) Including charge penetration effects in molecular modeling. J Chem Theory Comput 6:3330-3342

26. Esterhuysen C, Heßelmann A, Clark T (2017) Trifluoromethyl: an amphiphilic noncovalent bonding partner. ChemPhysChem 18: $772-784$

Publisher's note Springer Nature remains neutral with regard to jurisdictional claims in published maps and institutional affiliations. 